\title{
Confecção de planilha e análise de dados de raiva bovina do setor de virologia do CEPGM, da Empresa de Pesquisa Agropecuária do Estado do Rio de Janeiro - PESAGRO-RIO
}

Caroline Yungtay ${ }^{[a]}$, Danilo Machado Pacheco da Silva ${ }^{[a]}$, Phyllis Catharina Romijn ${ }^{[b]}$, Leda Maria Silva Kimura ${ }^{[b]}$, Alcir das Graças Paes Ribeir ${ }^{[b]}$, Lívia Maria Santos Rouge ${ }^{[b]}$, Renata Falcão Rabello da Costa ${ }^{[c]}$, Cathia Maria Barrientos Serra ${ }^{[a]}$, Elmiro Rosendo do Nascimento ${ }^{[a]}$, Nathalie Costa da Cunha $a^{[a]^{*}}$

\footnotetext{
[a] Faculdade de Veterinária, Universidade Federal Fluminense (UFF), Niterói, RJ, Brasil

[b] Setor de Virologia do Centro Estadual de Pesquisa em Sanidade Animal Geraldo Manhães Carneiro (CEPGM), PESAGRO-RIO, Rio de Janeiro, RJ, Brasil

[c] Secretaria de Estado de Agricultura, Pecuária, Pesca e Abastecimento do Estado do Rio de Janeiro, Rio de Janeiro, RJ, Brasil
}

*Autor correspondente

e-mail: nathalie.cunha@gmail.com

\section{Resumo}

A raiva é uma doença de caráter zoonótico, com letalidade de quase 100\%, e causa grandes prejuízos à pecuária, sendo seu controle e profilaxia de suma importância. 0 presente trabalho consistiu na confecção de um Banco de Dados relativo às informações sobre raiva animal provenientes do setor de virologia do Centro Estadual de Pesquisa em Sanidade Animal Geraldo Manhães Carneiro (CEPGM) da PESAGRO-RIO e sua posterior análise, com o intuito de que os resultados obtidos possam contribuir para o controle e profilaxia da raiva humana e animal. A partir de formulários de entrada do Setor de Virologia do CEPGM da Empresa de Pesquisa Agropecuária do Estado do Rio de Janeiro - PESAGRO-RIO, para confirmação laboratorial de raiva em herbívoros foi confeccionado em programa Excel ${ }^{\circledR}$ um banco de dados com resultados referentes aos anos de 2013 ao primeiro semestre do ano de 2016. Realizou-se análises descritivas dos dados e as análises estatísticas foram realizadas por meio de pacote BioEstat ${ }^{\circledR}$, utilizando-se o teste de qui-quadrado. 0 banco formado foi construído de dados qualitativos e quantitativos que serviram como matéria-prima para a realização de análises, totalizando 23 variáveis. Foram avaliadas no presente trabalho 5 variáveis, consideradas as mais relevantes para um estudo preliminar. Observou-se que foram confirmados 124 casos, por meio de imunofluorescência direta, dentre 199 casos suspeitos (62,31\%). A distribuição dos casos confirmados conforme as mesorregiões foram: Metropolitana do Rio de Janeiro (13,71\%), Noroeste Fluminense (33,06\%), Norte Fluminense (12,10\%), Centro Fluminense (16,94\%), Baixadas $(2,42 \%)$, Sul Fluminense $(13,71 \%)$ e Zona da Mata Mineira (8,06\%). Foi observado um maior número de casos na mesorregião Noroeste Fluminense, diferenciando-se estatisticamente das demais mesorregiões. Na 
mesorregião das Baixadas foi onde detectou-se os menores índices, diferindo-se estatisticamente, desta maneira, das mesorregiões Centro Fluminense e Norte Fluminense. Quanto ao sexo dos animais verificou-se a ocorrência de raiva distribuída em 76,61\% das fêmeas e 24,19\% dos machos. A idade média foi de 36,44 meses ( \pm 3 anos), com desvio padrão de 29,38. Verificou-se que no verão ocorreram $24,19 \%$ dos casos confirmados, no outono $18,55 \%$, inverno $30,65 \%$ e na primavera foram identificados $26,61 \%$ casos. A raiva ainda é uma enfermidade preocupante para a saúde pública e a raiva em herbívoros ainda tem o agravante de provocar prejuízos econômicos na cadeia de produção, o que nos torna impulsionados a manter uma vigilância epidemiológica ativa em qualquer circunstância. Importante ressaltar que na mesorregião Noroeste há uma Unidade Avançada do CEPGM, um polo de recebimento de amostras de toda a mesorregião Noroeste que proporciona a chegada de grande número de exames para raiva em detrimento de outras regiões onde não há esta facilidade. Esta informação é relevante no sentido que em outras mesorregiões há provavelmente casos subnotificados. 